\title{
The heart and lungs at extreme altitude
}

Severe chronic hypoxaemia occurs at sea level in persons with respiratory diseases such as pulmonary parenchymal diseases, upper airway obstruction, sleep apnoea, and hypoventilation. These are known to cause life threatening complications of hypoxaemia including altered metabolism, mental aberrations, pulmonary and systemic hypertension, right heart failure, arrhythmias, and considerable polycythaemia. Because of airway or parenchymal lung dysfunction, carbon dioxide retention, and the frequent presence of complicating cardiac diseases, it is difficult to identify the impact of the hypoxia itself on respiration and the circulation in patients. However, as these organ systems move oxygen from the ambient air to lung capillary blood and from the lung to systemic capillaries, it is important for respiratory physicians and cardiologists to know how they are affected by the hypoxia.

There are reasons to suspect that the heart might be adversely affected by hypoxaemia. In chronic obstructive lung disease accompanied by hypoxia and hypercapnia right heart failure often occurs when pulmonary arterial pressure is only modestly elevated. In contrast, when hypoxia and hypercapnia are absent, as in primary pulmonary hypertension, heart failure does not usually occur until pulmonary pressures are more significantly elevated. In healthy persons at high altitude a decrease in maximum oxygen uptake is accompanied by a decrease in maximal heart rate and a reduction in maximal cardiac output, raising the possibility that hypoxia-related cardiac malfunction is an important cause of exercise limitation.

Hypoxia-induced pulmonary hypertension is well recognised in the lung. When lung disease is present, however, it is not clear how much of the pressure elevation is due to the hypoxia and how much to destruction of parenchyma and its vascular bed. Furthermore, the possibility that pulmonary endothelial or epithelial function might be adversely affected is suggested by the occurrence of high altitude pulmonary oedema in healthy persons who ascend too rapidly to high altitude.

One approach to separating the effects of hypoxia from those of accompanying disease has been to study healthy persons at high altitude to observe the effects of hypoxia on the heart and lungs. The most complete analysis involving severe hypoxaemia was Operation Everest II (OE II), a chamber study ${ }^{12}$ performed in 1985 in which subjects breathed air decompressed for six weeks to the equivalent of $8848 \mathrm{~m}$. It was named after a study in 1946, Operation Everest. Now that several years have passed and more than 40 papers have been published from OE II, it is appropriate to review specifically what was learned relative to the effects of severe hypoxia on the heart and lungs.

\section{Ventilation, lung volumes and gas exchange}

The drive to breathe is normally preserved during several weeks of chronic severe hypoxia. For example, in OE II ventilation was well regulated, indicating good function of the carotid body, its neural connections, chest bellows function, air flow through large airways, ${ }^{3-5}$ and a profound fall in arterial $\mathrm{PCO}_{2}$ with increasing altitude compatible with an appropriate increase in effective ventilation (table). Directly measured arterial pH at the "summit" was less alkalotic than had been expected from a previous estimate. ${ }^{6}$ Air flow was not limited by bronchoconstriction as maximum mid expiratory flow rates were those expected for the reduced air density. Maintenance of normal (and even increased) hypoxic ventilatory drive, ${ }^{7}$ and the absence of respiratory muscle fatigue, ${ }^{58}$ were fortunate because, without the increase in ventilation, the fall in ambient $\mathrm{PO}_{2}$ would have been fatal.

Given normal flow rates, however, a restrictive lung defect was suggested by the progressively decreasing forced vital capacity (FVC) with increasing altitude. ${ }^{3}$ The absolute decrement averaged nearly 0.61 , about half of which was probably the result of an increased central blood volume and half of lung oedema. Chest radiographic findings (figure) showing prominent hilar pulmonary arteries, and the prompt increase of 0.31 in vital capacity on returning to sea level from $8848 \mathrm{~m}$, suggested an increase in the central blood volume. Interstitial oedema was suggested by chest radiography showing a perihilar haze, micronodules, and peribronchial cuffs (figure), and by the progressive increase in vital capacity during the first two days after return to sea level.

The pulmonary hypertension and interstitial oedema severely and adversely affected matching of ventilation and perfusion. ${ }^{10}$ Interstitial oedema probably contributed to poor ventilation of some alveoli ${ }^{10}$ and the lack of oxygen-related pulmonary vasomotor control ${ }^{11}$ contributed to overperfusion of poorly ventilated areas. The inherent diffusion limitation of oxygen transport at altitude was therefore compounded by reduced lung vital capacity, impaired vascular control, and increased interstitial water, all of which contributed to the arterial hypoxaemia.

So what was learned about the lung? In extreme hypoxia lung function deteriorated in all subjects. This contrasts with fulminant high altitude pulmonary oedema which develops in only a few individuals at $3000 \mathrm{~m}$. Conventional wisdom has been that the lung oedema and $\dot{\mathrm{V}} / \mathbf{Q}$ mismatch which can accompany a few days of hypoxia is not sustained during several weeks of exposure. Such a view may be too simple. The studies of OE II indicated that interstitial oedema, pulmonary hypertension, and impaired vasomotor control adversely affected

Resting measurements at several barometric pressures $\left(P_{B}\right)$ in Operation Everest II

\begin{tabular}{|c|c|c|c|c|c|c|c|c|c|c|}
\hline $\begin{array}{l}P_{B} \\
(m m ~ H g)\end{array}$ & $\begin{array}{l}\text { Altitude } \\
(m)\end{array}$ & $\begin{array}{l}\mathrm{PaO}_{2} \\
(\mathrm{kPa})\end{array}$ & $\begin{array}{l}\mathrm{PaCO}_{2} \\
(\mathrm{kPa})\end{array}$ & $p H a$ & $\begin{array}{l}\dot{V} E \\
(l / \text { min })\end{array}$ & $\begin{array}{l}F V C \\
(\%)\end{array}$ & $H R$ & $\begin{array}{l}R A \\
(m m H g)\end{array}$ & $\begin{array}{l}L A \\
(m m H g)\end{array}$ & $\begin{array}{l}P A P \\
(m m H g)\end{array}$ \\
\hline $\begin{array}{l}760 \\
429 \\
347 \\
282 \\
252\end{array}$ & $\begin{array}{r}0 \\
4800 \\
6300 \\
8100 \\
8848\end{array}$ & $\begin{array}{r}13 \cdot 7 \\
6 \cdot 3 \\
5 \cdot 2 \\
4 \cdot 6 \\
4 \cdot 0\end{array}$ & $\begin{array}{l}4.5 \\
3.3 \\
2.6 \\
1.6 \\
1.5\end{array}$ & $\begin{array}{l}7.43 \\
7.46 \\
7.50 \\
7.53 \\
7.56\end{array}$ & $\begin{array}{l}11 \\
15 \\
21 \\
37 \\
42\end{array}$ & $\begin{array}{r}100 \\
96 \\
92 \\
87 \\
86\end{array}$ & $\begin{array}{r}64 \\
71 \\
85 \\
94 \\
101\end{array}$ & $\begin{array}{l}1 \\
1 \\
2\end{array}$ & $\begin{array}{l}7 \\
7 \\
8\end{array}$ & $\begin{array}{l}15 \\
24 \\
34 \\
33\end{array}$ \\
\hline
\end{tabular}

$\mathrm{PaO}_{2}, \mathrm{PaCO}_{2}=$ arterial oxygen and carbon dioxide tension; $\mathrm{VE}=$ minute ventilation; $\mathrm{FVC}=$ forced vital capacity; HR=heart rate; $\mathrm{RA}=$ right atrial pressure; $\mathrm{LA}^{2}=$ pulmonary wedge pressure; $\mathrm{PAP}=$ pulmonary arterial pressure. 

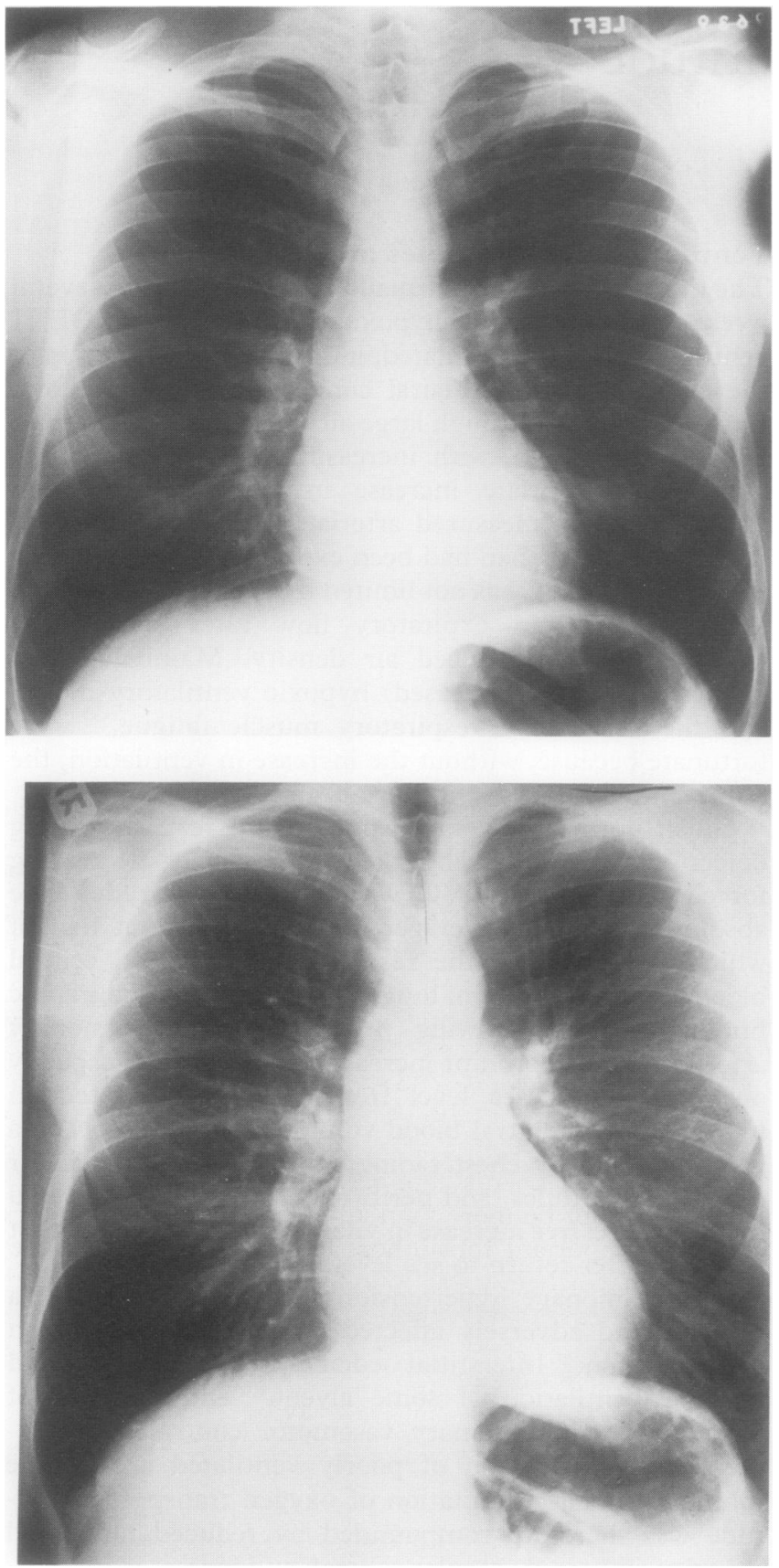

Chest radiographs in one subject taken before (top) and within one hour after exposure (bottom) over 40 days to increasing simulated altitudes to $8848 \mathrm{~m}$. Reproduced with permission from the American Review of Respiratory Disease.

$\dot{V} / \dot{Q}$ matching in all subjects, even after several weeks at altitude. Although it has long been known that chronic hypoxia elevates pulmonary arterial pressure, the impaired vascular function and the suggestion of interstitial oedema indicate that the lung may be less tolerant of chronic alveolar hypoxia than has previously been thought.

\section{Cardiovascular function}

The heart appeared to fare better. ${ }^{12}$ Resting heart rate increased and there was a trend towards an increased resting cardiac output, but output at maximum effort was half that at sea level. Despite the increased pulmonary arterial pressure at high altitude, the right atrial pressure was not increased (table). Systemic arterial pressure was maintained and pulmonary wedge pressure did not increase. Starling curves constructed from the ventricular filling pressures and stroke volumes indicated that both right and left ventricular function were normal at rest and during exercise (even to maximum effort) at all altitudes, including the equivalent of the summit. ${ }^{12}$

Echocardiography ${ }^{13}$ showed that the size of the left ventricular cavity decreased at altitude with the resting end diastolic volume shrinking by at least $25 \%$ at rest and during exercise. Despite the smaller left ventricular cavity at altitude, the left ventricular ejection fraction on exercise increased from $69 \%$ at sea level to $79 \%$ at $8100 \mathrm{~m}$. Circulating noradrenaline levels doubled at altitude. The findings showed that "despite reduced preload, right ventricular systolic hypertension, and severe cardiac hypoxaemia, left ventricular systolic function is maintained or somewhat enhanced in association with augmented sympathetic activity" at high altitude. ${ }^{13}$ Taken together the cardiac data suggested that both rate and pump functions of the heart were maintained at extreme altitude, both at rest and during exercise.

If the heart functions so efficiently, one wonders why maximal oxygen uptake is drastically reduced at extreme altitude and the maximum cardiac output is reduced. The answer is that exercise limitation is determined differently at sea level and at high altitude. ${ }^{14}$ While cardiac output is normally the most sensitive determinant of exercise performance at sea level, it is less important at altitude. Analysis indicates that if the maximum cardiac output at the summit was increased by $50 \%$ to equal that at sea level, maximum oxygen uptake would increase by only $3 \%$. The potential advantage of increasing output would be offset by the reduced transit time of blood in the pulmonary capillaries, which would worsen the diffusion limitation for oxygen. Thus, low inspired $\mathrm{Po}_{2}(5.6 \mathrm{kPa})$ on the summit of Mount Everest limits maximal oxygen uptake more by respiratory than circulatory mechanisms.

Normal heart function in young men at altitude does not directly apply to patients with obstructive lung disease because even equivalent hypoxaemia and pulmonary hypertension occurs in older persons, is of longer duration, and is accompanied by carbon dioxide and fluid retention. Hypercapnia is not only associated with fluid retention in normal persons ${ }^{15}$ and those with lung disease, ${ }^{16}$ but it also potentiates hypoxic pulmonary hypertension and subsequent right heart failure. ${ }^{16} \mathrm{~A}$ circulatory system which functions well in hypoxia will probably function less well when there is accompanying hypercapnia.

Operation Everest II was a unique experiment which allowed measurement of the cardiac and ventilatory responses in normal persons exposed to chronic severe hypoxaemia. Even at the "summit" the normal heart showed robust function, while the lung did not. Such information, taken together with clinical studies in patients,can add to our understanding of the pathophysiology of heart and lung disease.

Reprints will not be available.

University of Colorado,

Health Sciences Center,

Denver, Colorado 80260, $U S A$

University of California, San Diego, California 92093. $U S A$

PD WAGNER

1 Houston CS, Sutton JR, Cymerman A, Reeves JT. Operation Everest II : man at extreme altitude. $\mathcal{F}$ Appl Physiol 1987;63:877-82.

2 Reeves JT, Houston CS, Sutton JR. Operation Everest II: resistance and susceptibility to chronic hypoxia in man. $\mathcal{F} R$ Soc Med 1989;82:513-4. 
3 Welsh CH, Wagner PD, Reeves JT, Lynch D, Cink TM, Armstrong J, et al. Spirometric and radiographic changes in acclimatized humans at simulated high altitudes. Am Rev Respir Dis 1993;147:1239-44.

4 Sutton JR, Reeves JT, Wagner PD, Groves BM, Cymerman A, Malconian $\mathrm{MK}$, et al. Operation Everest II: oxygen transport during exercise at extreme simulated altitude. $\mathcal{F}$ Appl Physiol 1988;64:1309-21.

5 Malconian MK, Rock PB, Reeves JT, Cymerman A, Houston CS. Operation Everest II: gas tensions in expired air and arterial blood at extreme tion Everest II: gas tensions in expired air and arteria

6 West JB, Hackett PH, Maret KH, Milledge JS, Peters RM, Pizzo CJ, et al. Pulmonary gas exchange on the summit of Mount Everest. $\mathcal{F}$ Appl Physiol 1983;55:678-87.

7 Schoene RB, Roach RC, Hackett PH, Sutton JR, Cymerman A, Houston $\mathrm{CH}$. Operation Everest II: ventilatory adaptation during gradual decompression to extreme altitude. Med Sci Sports Exerc 1990;22:804-10.

8 Cymerman A, Reeves JT, Sutton JR, Rock PB, Groves BM, Malconian $\mathrm{MK}$, et al. Operation Everest II: maximal oxygen uptake at extreme altitude. F Appl Physiol 1989;66:2446-53.

9 Roy SB, Guleria JS, Khanna PK, et al. Hemodyamic studies in high altitude pulmonary edema. Br Heart $\mathcal{f}$ 1969;31:52-8.
10 Wagner PD, Sutton JR, Reeves JT, Cymerman A, Groves BM, Malconian MK. Operation Everest II: pulmonary gas exchange during a simulated ascent of Mt. Everest. f Appl Physiol 1987;63:2348-59.

11 Groves BM, Reeves JT, Sutton JR, Wagner PD, Cymerman A, Malconian MK, et al. Operation Everest II: elevated high-altitude pulmonary resistance unresponsive to oxygen. $f$ Appl Physiol 1987;63:521-30.

12 Reeves JT, Groves BM, Sutton JR, Wagner PD, Cymerman A, Malconian $\mathrm{MK}$, et al. Operation Everest II: preservation of cardiac function at extreme altitude. $\mathcal{J}$ Appl Physiol 1987;63:531-9.

13 Suarez J, Alexander JK, Houston CS. Enhanced left ventricular systolic performance at high altitude during Operation Everest II: $A m \mathcal{F}$ Cardio 1987;60:137-42.

14 Wagner PD. Algebraic analysis of determinants of $\mathrm{Vo}_{2}$ max. Respir Physiol 1993;93:221-37.

15 Grover RF, Reeves JT, Maher JT, McCullough RE, Cruz JC, Denniston $\mathrm{JE}$, et al. Maintained stroke volume but impaired arterial oxygenation in man at high altitude with supplemental $\mathrm{CO}_{2}$. Circ Res 1976;38:391-6.

16 Filley GF, Beckwith HJ, Reeves JT, Mitchell RS. Chronic obstructive pulmonary disease II. Oxygen transport in two clinical types. $\mathrm{Am} \mathcal{F} \mathrm{Med}$ 1968;44:26-38.

\section{Indexing Thorax}

The method of indexing papers in Thorax is to be changed. Papers will now be indexed by a keyword system and authors are asked to help with this by supplying up to three keywords when submitting their manuscripts. Some modification of them may be necessary by the Editor or Technical Editor.

The index will be published, as usual, at the end of the December issue, but the format will be different with the full title of the paper appearing after each keyword. The author index will no longer include the titles of the papers and will become a list of authors and page numbers only.

A keyword is a word (or phrase) that identifies the subject matter of the paper. Choosing keywords would not appear to be difficult, but there are problems with synonyms (for example, pulmonary and lung), phrasal headings (for example, lung cancer and cancer, lung), proprietary and pharmaceutical names of drugs, Latin words, and assorted lay terms. In Thorax it has been decided that "lung" should be used in preference to "pulmonary" and that "lung cancer" is preferable to "cancer, lung". In general it is better not to split accepted compound terms such as "chronic obstructive lung disease". As the subject of the journal is the thorax, the words "thorax" and "thoracic" should not be used except, perhaps, in "thoracic unit" or "thoracic surgery". Some shortened forms such as DNA, AIDS, HIV and cAMP are acceptable. Greek letters are not generally used in alphabetisation except in a few instances such as alpha-fetoprotein and beta-adrenoceptor. General terms such as "clinical", "complications", "adverse effects", and "patients" are best avoided.

This cannot be more than an attempt to guide authors, but it is important for authors to remember that, if they wish to have their work found easily in the index, they should consider their choice of keywords carefully. 